\title{
"Effectiveness of Planned Teaching Programme on Knowledge of Early Detection of Breast Cancer Among School Teachers"
}

\author{
Ms. Salomy Chacko \\ Lecturer,St.Luke's Hospital,College of Nursing Shrirampur,Maharashtra
}

\begin{abstract}
:
Back ground of the study: Medical advances have shown that one-third of all cancers are preventable and further one third, if diagnosed sufficiently early, is potentially curable. This observation demands that cancer control should be of increasing priority in the healthcare programs of developing countries. One potentially important strategy in reducing breast cancer mortality is the use of screening to achieve earlier detection of cancer. The main methods of screening involve mammography, clinical breast examination (CBE), and breast self-examination (BSE). Despite the advent of modern screening methods, more than $90 \%$ of cases of cancers of the breast are detected by women themselves, stressing the importance of breast self examination. ${ }^{\text {II Planned }}$ teaching program is one of the methods through which awareness can be created among women regarding early detection of breast cancer.

Methodology: The aim of the study was to assess the knowledge of early detection of breast cancer among school teachers. An evaluative approach with pre-experimental (one group pre-test post-test) design was used for the study. The sample consisted of 60 school teachers selected by purposive sampling technique. Pre-test was conducted by administering a structured knowledge questionnaire. After the pre-test, the PTP was administered and on the eight day post test was conducted. The collected data was analyzed by using descriptive and inferential statistics (' $t$ ' test).

Results: The mean post-test knowledge score $(O 2=24.05)$ was higher than the mean pre-test knowledge score $(O 1=12.48)$. The computed ' $t$ ' value (24.14) was higher than the table value $(t(59)=1.67)$ at 0.05 level of significance, suggesting that the PTP was effective in increasing the knowledge of female teachers on early detection of breast cancer.

Interpretation: The result showed that the PTP was effective in increasing the level of knowledge of teachers on early detection of breast cancer.

Conclusion: The findings of the study showed that the knowledge of teachers was average before the administration of the PTP. The post-test knowledge scores showed significant increase in the level of knowledge of teachers. Hence the PTP is an effective teaching method for providing information and improving the knowledge of teachers.
\end{abstract}

Keywords: Effectiveness; PTP; Knowledge; Early detection; Breast cancer; Schoolteachers.

\section{Introduction}

The female body is one of nature's most wonderful and complex creations. It is the origin of all human life. A woman's journey in life is punctuated by many milestones; childhood, puberty, matrimony, pregnancy, childbirth, motherhood and each milestone special in its own way. The female reproductive system includes the external genital organs and the internal reproductive organs and breast is one of the external genital organs. The female breasts contain the mammary glands, which secrete milk. Although the primary function of the breasts is production of milk, the female breasts play an important part in female sexual behaviour. Stimulation of the female breasts enhances the sexual pleasure of a woman. However breast can become a source of malaise, soreness and discomfort.

Breast tumours are caused by a genetic defect in a cell which causes it to multiply uncontrollably, leading to the formation of a lump of tissue. In some cases, tumours are benign, with little risk of spreading to neighbouring organs, and some check on their growth. Benign tumours can still cause health problems, depending on their location, and they may also be viewed as cosmetic defects. Malignant tumours, on the other hand, have the potential to metastasize and they grow very rapidly and aggressively. ${ }^{1}$ There are several different forms of benign breast tumours, including phyllodes tumours, granular cell tumours, papillomas, and fibro adenomas. All of these benign growths can cause lumps in the breast or around the milk duct. Classically, a benign breast tumour has smooth edges when it is palpated, and it can be moved around in the breast tissue. Some women also experience fibrocystic changes, lumps in their breasts which wax and wane with the menstrual cycle. ${ }^{1}$ Breast cancer is a cancer that starts in the breast, usually in the inner lining of the milk ducts or lobules. There are different types of breast cancer, with different stages of spread, aggressiveness, and genetic makeup. Breast cancer is defined as a group of malignant diseases that commonly occur in the female breast and 
infrequently in the male breast. ${ }^{2}$ Breast cancer is one of the commonest causes of deaths in many developed counties in the middle aged women and is becoming frequent in the developing countries too. ${ }^{4}$ Worldwide, breast cancer is the second most common type of cancer after lung cancer (10.4\% of all cancer incidences) and the fifth most common cause of cancer death. The American cancer society estimated that 182,460 women in the United States were diagnosed with breast cancer in 2008 and that 40,480 women died of the disease during the year. Estimated new cases and deaths from breast cancer in the United States in 2010: New cases: 207,090 (female); 1,970 (male). Deaths: 39,840 (female); 390 (male). ${ }^{17}$ Among all cancers diagnosed in women, more than $40 \%$ is breast cancer by the age of $40,20 \%$ by the age of 30 , and slightly more than $2 \%$ by 20 years of age. One out of eight females is exposed to the risk of developing breast cancer ${ }^{3}$.

Breast cancer is particularly common in women from affluent class. As it involves the sexually important part of the body its treatment sometimes is physically and emotionally mutilating. It affects not only the individuals but also deeply involves the families. It is dreadful for reasons, firstly it is a cancer with relatively bad prognosis and secondly, it implies the necessity of mutilating surgery on a most important body part of the women. The announcement of the diagnosis of breast cancer is always distressing, as with breast cancer the symbol of feminity is compromised ${ }^{4}$. In our country, because of multiple factors, patients come quite late when the disease is already advanced. With such a situation the survival rate goes as low as $0-25 \%$, whereas when early lesions identified and treated the survival rate improves to almost $95 \%$ in addition to good cosmetic results. ${ }^{4}$

Breast cancer accounts for 19-34\% of all cancer cases in women in India. According to National cancer registries and Regional Cancer Centres, it is the commonest cancer among women in Delhi, Mumbai, Ahmedabad, Kolkota and Trivandrum. In all other cancer registries, it is listed as the second most cancer among women. Moreover, data from national and regional cancer centres from 1984 to 2002 also show that there is an increase in the incidence of breast cancer and found to be gradually overtaking cancer of the cervix ${ }^{6,7}$.

The cause of breast cancer is unknown, but research shows that certain risk factors are associated with the disease. A risk factor is something that increases the chance of getting a disease or condition. Risk factors for breast cancer include: Sex: Female, although men can also get breast cancer, increasing age, 40 and above, personal history of breast cancer, family members with breast cancer, changes in breast tissue, changes in certain genes, increased exposure to oestrogen over a lifetime through: early onset of menstruation, late onset of menopause, no childbearing or late childbearing, absence of breastfeeding, taking hormone replacement therapy for long periods of time, tobacco use, increased breast density, radiation therapy before the age of 30 years old, overuse of alcohol, obesity, diet containing more of fatty food, being on the contraceptive pill for a prolonged period. $^{2,8,9}$

A cross-sectional study was carried out to determine the knowledge and practices of breast cancer screening (BCS) among 425 female secondary school teachers from 20 selected secondary schools in Selangor, Malaysia. A self-administered, structured questionnaire was used for data collection. This study showed moderate to low knowledge on Breast Cancer (BC) and BCS among teachers. Only 19\%, 25\% and 13.6\% eligible women performed BSE, clinical breast examination (CBE) and mammography respectively, on a regular basis. Level of breast cancer knowledge was significantly associated with BSE ( $<<0.001)$. The study concluded by stating that efforts are needed to increase knowledge and remove misconceptions about breast cancer and screening practices among Malaysian women. ${ }^{10}$

A pre experimental one group pre-test- post-test design undertaken in CSI Kalyani Multispeciality hospital School of nursing, Mylapur, Chennai to assess the effectiveness of structured teaching programme on breast self examination for early detection of breast cancer among nursing assistant students. The samples comprised of 60 nursing assistant students selected by using simple random sampling technique. The data was collected by using structured questionnaire, Likert scale and an observation checklist to measure the knowledge, attitude and practice of breast self examination. The study revealed that $38.33 \%$ of students had inadequate knowledge and $55.33 \%$ of them had negative attitude and $80 \%$ of them had poor practice. After the intervention $96.67 \%$ had adequate knowledge, $78.33 \%$ had moderately favourable attitude and majority of them $86.67 \%$ good practice 5 .

\section{Objectives}

- To determine the level of knowledge on early detection of breast cancer among school teachers using structured knowledge questionnaire.

- To find the effectiveness of planned teaching programme on early detection of breast cancer among school teachers in terms of gain in knowledge score.

- To find the association between the pre-test knowledge score and selected baseline characteristics (age, marital status, number of children if married and previous source of information). 


\section{Research Methodology}

3.1Research approach: Evaluative approach

3.2Research design: Pre-experimental, one group pre test-post test design

3.3Population: School teachers

3.4Sample: 60 primary and secondary school teachers

3.5Sampling technique: Purposive sampling

3.6Dependent variable: Knowledge of school teachers

3.7Independent variable: Planned teaching programme

3.8Analysis: Descriptive and inferential statistics

3.9Sampling criteria

\section{Inclusion criteria}

- Teachers working as fulltime employees

- Teachers willing to participate in the study.

- Teachers between the age group of 21-60 years.

\section{Hypotheses}

All hypotheses will be tested at 0.05 level of significance.

$\mathrm{H}_{1}$ : There will be significant difference between the mean pre-test and post-test knowledge scores on early detection of breast cancer among school teachers.

$\mathrm{H}_{2}$ : There will be significant association between the mean pre-test knowledge score and selected baseline characteristics (age, marital status, number of children if married and previous source of information)

\section{Assumptions}

The study assumes that:

- School teachers may have some knowledge on early of detection breast cancer.

- School teachers play an important role in communicating information on early detection of breast cancer.

\section{Results}

Table4. 1: Percentage distribution of demographic characteristics

\begin{tabular}{|l|l|}
\hline Demography characteristics & Percentage \\
\hline Age & \\
\hline $21-30$ yea1rs & $40 \%$ \\
\hline $31-40$ years & $40 \%$ \\
\hline $41-50$ years & $15 \%$ \\
\hline $51-60$ years & $5 \%$ \\
\hline Marital status & \\
\hline Married & $68.3 \%$ \\
\hline Single & $30 \%$ \\
\hline Widows & $1.7 \%$ \\
\hline Living separate & 0 \\
\hline No. of children & \\
\hline One & $32 \%$ \\
\hline Two & $49 \%$ \\
\hline Three and above & $2 \%$ \\
\hline No children & $17 \%$ \\
\hline Previous source of information & \\
\hline Mass media & $61.7 \%$ \\
\hline Family and friends & $5 \%$ \\
\hline No & $33.3 \%$ \\
\hline Health personnel & 0 \\
\hline
\end{tabular}

Table4.2: Assessment of the level of knowledge of teachers on early detection of breast cancer

\begin{tabular}{|l|l|l|l|l|}
\hline & Grading of & Percentage of & & \\
\hline & knowledge level & Scores & Frequency & Percentage \\
\hline & Poor (0-12) & $0-40$ & 27 & 45.0 \\
\hline & Average (13-18) & $41-60$ & 31 & 51.7 \\
\hline & Good (19-24) & $61-80$ & 2 & 3.3 \\
\hline & Very good (25-30) & $81-100$ & 0 & 0.0 \\
\hline
\end{tabular}

The above table depicts that Assessment of the level of knowledge of teachers on early detection of breast cancer revealed that majority $31(51.7 \%)$ of the teachers had average knowledge, and $27(45 \%)$ of the teachers had poor knowledge, whereas $2(3.3 \%)$ of the teachers possessed good knowledge and no one possessed very good knowledge. 
Table 4.3: Description of area-wise mean, SD, mean percentage knowledge score

\begin{tabular}{|l|l|l|l|l|l|l|}
\hline SI. & & Maximum & & & Mean & Level of \\
\hline No. & Knowledge Area & Score & Mean & SD & Percentage & knowledge \\
\hline 1. & Anatomy of breast & 7 & 2.45 & 1.254 & 35.00 & Poor \\
\hline & and meaning, site & & & & & \\
\hline & of occurrence & & & & & \\
\hline 2 & Risk factors, signs & 7 & 2.70 & 1.331 & 38.57 & Poor \\
\hline & and symptoms & & & & & \\
\hline 3 & Early detection & 16 & 7.33 & 1.847 & 45.83 & Average \\
\hline & Overall & 30 & 12.48 & 3.000 & 41.61 & Average \\
& & & & & & \\
\hline
\end{tabular}

The data presented in Table 3 indicates that out of 30 maximum possible scores the total mean score was 12.48 , which is $41.61 \%$ of maximum score. The highest mean percentage (45.83) was found in the area of early detection with mean \pm SD of $7.33 \pm 1.847$ respectively. Area-wise mean percentage knowledge score in the area of anatomy and meaning of breast cancer was 35\% with mean \pm SD of $2.45 \pm 1.254$ and in the area of risk factors and signs and symptoms was $38.57 \%$ with mean \pm SD of $2.70 \pm 1.331$ respectively.

Table 4.4: Area-wise effectiveness of planned teaching programme with mean, SD and mean percentage of pretest post-test knowledge scores of teachers

\begin{tabular}{|c|c|c|c|c|c|c|}
\hline \multirow{3}{*}{ Knowledge } & & & & & \multicolumn{2}{|l|}{ Effectiveness } \\
\hline & \multicolumn{2}{|l|}{ Pre-test $\left(\mathrm{O}_{1}\right)$} & \multicolumn{2}{|c|}{ Post-test $\left(\mathrm{O}_{2}\right)$} & \multicolumn{2}{|c|}{$\left(\mathrm{O}_{2}-\mathrm{O}_{1}\right)$} \\
\hline & \multirow[t]{2}{*}{ Mean \pm SD } & \multirow[t]{2}{*}{ Mean \% } & \multirow[t]{2}{*}{ Mean \pm SD } & \multirow[t]{2}{*}{ Mean \% } & \multirow[t]{2}{*}{ Mean \pm SD } & \multirow[t]{2}{*}{ Mean\% } \\
\hline Area & & & & & & \\
\hline Anatomy and & $2.45 \pm 1.254$ & 35 & $5.38 \pm 1.403$ & 76.90 & $2.93 \pm 1.65$ & 41.90 \\
\hline \multicolumn{7}{|l|}{ Meaning } \\
\hline Risk factors, & $2.70 \pm 1.331$ & 38.57 & $5.60 \pm 1.224$ & 80.00 & $2.90 \pm 1.36$ & 41.43 \\
\hline \multicolumn{7}{|l|}{ signs and } \\
\hline \multicolumn{7}{|l|}{ Symptoms } \\
\hline Early & $7.33 \pm 1.847$ & 45.83 & $13.07 \pm 1.885$ & 81.67 & $5.73 \pm 2.52$ & 35.83 \\
\hline \multicolumn{7}{|l|}{ Detection } \\
\hline Over all & $12.48 \pm 3.000$ & 41.61 & $24.05 \pm 3.207$ & 80.17 & $11.57 \pm 3.71$ & 38.56 \\
\hline
\end{tabular}

Comparison of area-wise mean and SD and mean percentage of the knowledge scores as presented in table 3 and figure 10, shows that in the area of anatomy and meaning the pre-test mean percentage knowledge score was $35 \%$ with mean \pm SD of $2.45 \pm 1.254$. The post-test mean percentage knowledge score was $76.90 \%$ with mean \pm SD of $2.93 \pm 1.65$ showing the maximum increase of $41.90 \%$ mean percentage knowledge score of teachers. In the area of risk factors and signs and symptoms 41.43 increase in the mean percentage knowledge score was observed with $38.57 \%$ in the pre-test and $80 \%$ in the post-test respectively

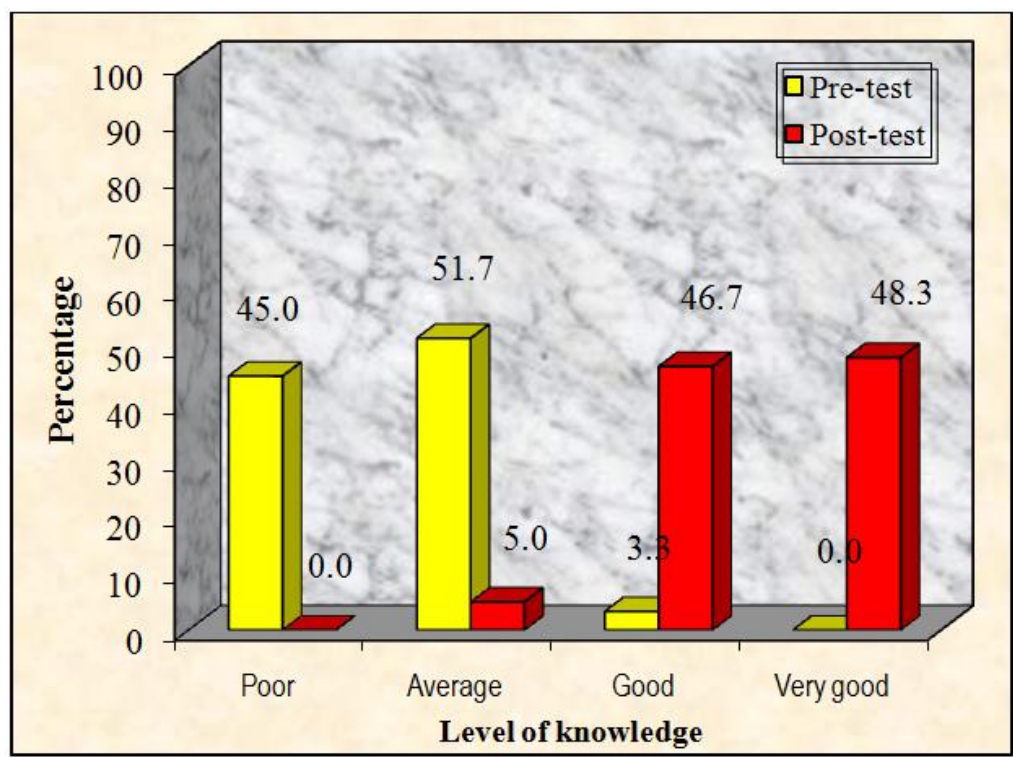

Figure 4.5: Area-wise effectiveness of planned teaching programme with mean, SD and mean percentage of pre-test post-test knowledge scores of teachers 
Table4.6: Chi-square test showing the association between pre-test knowledge score and selected baseline characteristics

\begin{tabular}{|c|c|c|c|c|c|}
\hline & \multicolumn{2}{|c|}{ Knowledge score } & \multirow{3}{*}{$\chi^{2}$} & \multirow[b]{3}{*}{ P value } & \multirow[b]{3}{*}{$\begin{array}{l}\text { Inferenc } \\
\text { e }\end{array}$} \\
\hline & & & & & \\
\hline Variable & < Median & $\geq$ Median & & & \\
\hline \multicolumn{6}{|l|}{ Age in years } \\
\hline $21-30$ & 10 & 14 & & & \\
\hline $31-40$ & 12 & 12 & 0.404 & 0.817 & NS \\
\hline $41-60$ & 5 & 7 & & & \\
\hline \multicolumn{6}{|l|}{ Marital status } \\
\hline Single/widow & 10 & 9 & \multirow[t]{2}{*}{0.654} & \multirow[t]{2}{*}{0.419} & \multirow[t]{2}{*}{ NS } \\
\hline Married & 17 & 24 & & & \\
\hline \multicolumn{6}{|c|}{ Number of children if married } \\
\hline None & 3 & 4 & & & \\
\hline One & 6 & 7 & 0.221 & 0.895 & NS \\
\hline Two and above & 8 & 13 & & & \\
\hline \multicolumn{6}{|c|}{ Previous source of Information } \\
\hline Got information & 18 & 22 & \multirow[t]{2}{*}{0.000} & \multirow[t]{2}{*}{1.000} & \multirow[t]{2}{*}{ NS } \\
\hline No information & 9 & 11 & & & \\
\hline \multicolumn{2}{|c|}{ Table value $5.99,3.84 ; \mathrm{P}<0.05$} & & & \multicolumn{2}{|c|}{$\mathrm{NS}=$ No Significance } \\
\hline
\end{tabular}

The data presented in table 5 reveal that calculated chi square values were less than the table value for all the variables. Hence it is inferred that there was no association between the pre-test knowledge score and the selected baseline characteristics. Hence the null hypothesis was accepted for all the baseline characteristics.

\section{Limitations of the study}

$\checkmark \quad$ The study sample was confined to only school teachers.

$\checkmark \quad$ Lack of random sampling technique hindered the generalization of the result.

$\checkmark$ A structured knowledge questionnaire was used for data collection, which restricts the amount of information that could be obtained from the respondents.

$\checkmark \quad$ The study did not have a control group. The investigator had no control over

$\checkmark \quad$ The events that took place between pre-test and post-test.

$\checkmark \quad$ No attempts were made to do the follow up to check the retention of knowledge of teachers.

\section{Suggestions}

- Health professional can accomplish seminars, workshop and training programmes on early detection of breast cancer.

- Planned teaching programme can be provided to teacher from pre-primary to higher secondary classes.

- Teaching programmes on early detection of breast cancer could be arranged for teachers by health care team in the schools and communities.

Recommendations: On the basis of findings of the study the following recommendations have been made:

\# The study could be replicated on a larger sample for generalizing the findings.

* An experimental study can be done with control group.

* A similar study can be conducted among non teaching women.

* A descriptive study can be conducted to assess the knowledge attitude and practice of teachers on early detection of breast cancer.

* A comparative study can be conducted both in urban and rural female population

\section{Conclusion}

The present health care delivery system emphasizes more on preventive rather than curative aspects. The study also implies that health personnel have to be properly trained on educating the school teachers regarding anatomy of breast, meaning of breast cancer, risk factors, signs and symptoms and early detection (BSE, CBE and mammogram) of breast cancer. Nurses have an understanding of the school teachers' role in educating their students and others in early detection of breast cancer. Nursing curriculum should be such that it prepares the prospective nursing students to assist the teachers in all aspects of their health care. The present nursing curriculum although includes content on breast cancer, it needs to lay further emphasis on early detection of breast cancer. The following conclusions were drawn based on the findings of the present study:

* BSE is cost effective and it can be practised by every woman for early detection.

Pre-test findings showed that teachers have deficient knowledge on early detection of breast cancer. 
* Planned Teaching Programme in the study was found to be effective in increasing knowledge of teachers and this motivated them for early detection.

* PTP with demonstration of breast self examination is an effective method of providing information. It was very much appreciated by the teachers and they suggested that this type of information can be given frequently to upgrade their knowledge to identify breast cancer and treat it at the earliest stage.

PTP is proved to be one of the effective teaching strategies.

There was no significant association between the knowledge and baseline characteristics. So it is needed to educate all women on early detection of breast cancer.

\section{Acknowledgement}

I acknowledge my deep sense of gratitude to my dear parents and friends for their constant support and encouragement.

\section{References}

[1]. What is a Benign Tumor? [online]. Available from: URL:http://www.wisegeek.com/what-is-a-benign-tumor.htm. [Accessed on 12.8.2010].

[2]. Black JM, Hawks JH. Medical-Surgical Nursing: clinical management for Positive outcomes. $8^{\text {th }}$ ed. Philadelphia: Reed Elsevier India Pvt Ltd; 2009.

[3]. Anders CK. Breast cancer before the age of 40. Seminars in Oncology 2009;36(3):237-49.

[4]. Sinha RK. How to avoid breast cancer. Nightingale Nursing Times 2004;5(1):16-29.

[5]. Amutha P. Effectiveness of structured teaching program on breast self examination for early detection of breast cancer. Nightingale Nursing Times 2010;6(2):41-4.

[6]. Somdatta P, Baridalyne N. Awareness of breast cancer in women of an urban resettlement colony. Indian Journal of Cancer 2008;45(4):2.

[7]. Marimuthu P. Projection of cancer incidence in five cities and cancer mortality in India. Indian Journal of Cancer 2008;45(1):4-7.

[8]. Smeltzer SC, Bare BG, Hinkle JL, Cheever KH. Brunner and Suddarth text book of Medical -Surgical Nursing. $11^{\text {th }}$ ed. New Delhi: Wolters Kluwer Pvt. Ltd; 2008

[9]. What are the risk factors for breast cancer?. [online]. Available from: URL: http://www.tennesseebreastcenter.com/faq/body.htm. [Accessed on 12.7.2010].

[10]. Anderson BO et al. Early detection of breast cancer in countries with limited resources. The Breast Journal 2003;9(2):51-9.

[11]. Kayode FO, Akande TM, Osagbemi GK. Knowledge, attitude and practice of breast self examination among female secondary school teachers in Illorin, Nigeria. European Journal of Scientific Research 2005;10(3):42. 